\title{
The use of self-assembled receptor layers in immunosensors
}

\author{
R. P. H. Kooyman and D. J. van den Heuvel \\ University of Twente, MESA Institute, Department of Applied Physics, P.O. Box 217, 7500 AE Enschede (Netherlands)
}

J. W. Drijfhout

University Hospital Leiden, Department of Immunohaematology and Bloodbank, P.O. Box 9600, 2300 RC Leiden (Netherlands)

G. W. Welling

University of Groningen, Laboratory of Medical Microbiology, Oostersingel 59, 9713 EZ Groningen (Netherlands)

\begin{abstract}
We demonstrate that a self-assembled monolayer consisting of an alkylthiol coupled synthetic peptide adsorbed to a gold substrate results in a sensitive receptor surface for specific recognition of protein molecules. The affinity constant of this binding is comparable with that of an antibody-antigen reaction. Evidence is found that such a receptor surface is capable of reversible binding.
\end{abstract}

\section{Introduction}

As has been demonstrated repeatedly [1], immunosensors appear to form an important subclass among the various chemical sensor systems that are under development. One of their attractive aspects is the fact that the sensing elements, the (monoclonal) antibodies, can be obtained using well known biotechnological procedures with a specific affinity to almost any particular target moleculc. Gencrally, specific affinity constants are of the order of $10^{8}-10^{10} \mathrm{M}^{-1}$, and thus these molecules, immobilized to some suitable substrate, provide a solid basis for a highly sensitive sensor system.

However, generally the binding between antibody and target molecule is essentially ireversible, implying that antibodies as receptors can only be used in batchtype assays. Moreover, immobilization procedures of the antibody involve the use of certain chemical groups situated at different locations of the molecule. This has the result that the antibody is not uniformly immobilized, resulting in a partial obstruction of antibody binding sites, and thus suboptimal specific affinity of the receptor surface. In addition, in the case when target molecules are relatively small, it can be a serious drawback for optical transducer principles which utilize the evanescent field that antibodies $(M W \approx 150 \mathrm{kD})$ are rather bulky in their dimensions.

In this paper we discuss whether the use of an ordered array of small synthetic peptides $(M W \approx 2 \mathrm{kD}$ ), mimicking the antibody binding site, can assist in the solution of the above-mentioned problems.

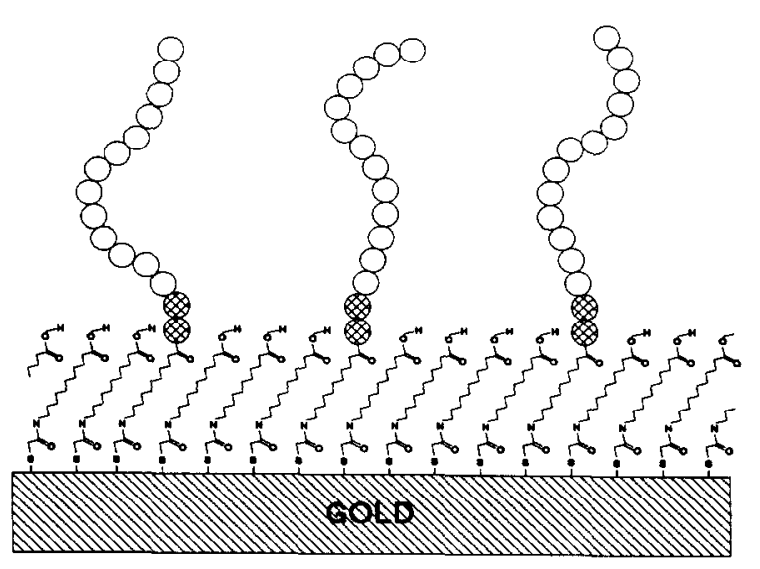

Fig. 1. Schematic depiction of an SAR formed from adsorbates $A$ and C. The peptide is scaled to the hydrophobic moiety. Lateral dimensions are not to scale.

We show that such an array can be conveniently immobilized on a gold substrate as a self-assembling monolayer [2-7] composed of a mixture of thiol-peptides and alkylthiols. The resulting self-assembling receptor layer (SAR) (for an impression of such a layer see Fig. 1) is characterized with respect to its specific affinity for the target molecule.

\section{Experimental details}

Peptides with well-defined amino-acid sequences that are expected to allow for specific recognition of the 
monoclonal antibody A16 [8] (compound A, a 12 amino-acid chain) and of lysozyme $[9,10]$ (compound B, a 13 amino-acid chain) respectively, were synthesized and coupled to a 12 membered alkylthiol, as described previously [11]. Also, the corresponding alkylthiol chains with the peptide moiety replaced by a hydroxygroup were prepared (compound C). These molecules are intended to provide a spatial separation of the peptides in the SAR ( $c f$. Fig. 1). Also, a compound D was synthesized, similar to compound B but with a different amino acid sequence. This "dummy" $D$, which is not expected to bind, can be considered as a reference molecule for the binding studies carried out with compound $\mathrm{B}$.

SARs were prepared on freshly evaporated gold layers (thickness approximately $50 \mathrm{~nm}$ ) by sequential adsorption of the constituent molecules $\mathrm{A} / \mathrm{C}$ or $\mathrm{B} / \mathrm{C}$. The adsorption process could be followed on-line in a surface plasmon resonance (SPR) set-up (see below), so that the actual surface coverage of the two adsorbates could be determined [11].

To study the binding events at the substrate-solution interface we used a home-built SPR set-up, equipped with a $\lambda=670 \mathrm{~nm}$ diode laser $[12,13]$. For a description of the physics of SPR and its application in binding studies we refer to previous work [14-16]. For the present purposes it suffices to mention that the angle $\theta_{\mathfrak{p}}$ under which a p-polarized light beam exhibits a minimum in reflectance when reflected at the glass-gold interface ( $c f$. Fig. 2) is a sensitive measure of the layer thickness on top of the gold layer. It can be calculated [16] that for protein adsorption an angular shift is obtained of approximately $0.2^{\circ}$ per nanometre of layer growth. Our present SPR set-up has a resolution of one millidegree. It should be mentioned that in the experimental results, presented in the following section, all angular shifts are normalized to $\lambda=632 \mathrm{~nm}$, to facilitatc comparison with previously published SPR results.

All experiments were done in a $0.1 \mathrm{M}$ phosphate buffer solution and, unless mentioned otherwise, at approximately $\mathrm{pH} 7$
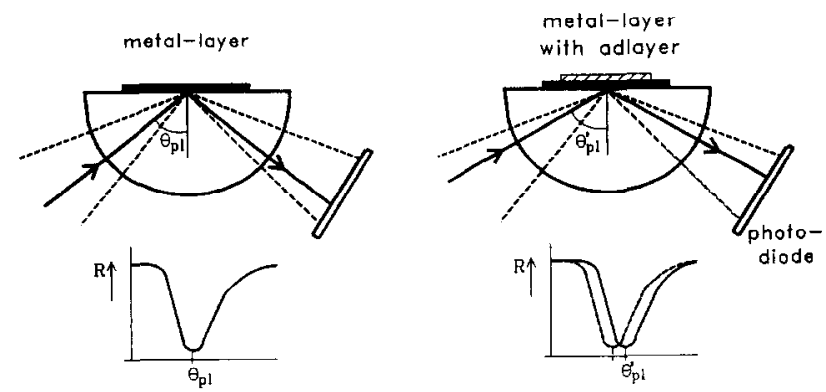

Fig. 2. Principle of the SPR experiment. For a bare layer of gold an angle of reflection minimum $\theta_{\mathrm{pl}}$ is found. The presence of a protein adlayer on top of the gold will result in an angle $\theta_{p 1}^{\prime}$.

\section{Results and discussion}

\subsection{SARs to an antibody}

In Fig. 3 the specific response of $7 \times 10^{-8} \mathrm{M}$ Mab-16 to different compositions of SAR is shown. A prominent maximum response ( $\Delta \theta=850 \mathrm{mdeg}$ ) is seen at a surface coverage of approximately $3 \mathrm{~mol} \%$ of compound $\mathrm{A}$. At this coverage the Mab-16 response corresponds to a layer growth of approximately $5 \mathrm{~nm}$, indicating that a complete monolayer is bound to the SAR. A control experiment in which $10^{-7} \mathrm{M}$ of the antibody anti-human serum albumin was allowed to interact with this SAR showed no response. In passing, we note that adsorption of the same concentration of Mab-16 to a bare gold layer results in an angle shift $\Delta \theta=450 \mathrm{mdeg}$; apparently, the nature of the protein interaction with gold is quite different from that with the SAR. The response pattern depicted in Fig. 3 can be rationalized by assuming that at approximately $3 \mathrm{~mol} \%$ $A$ the average nearest-neighbour distance between the different peptide receptors in the SAR is the smallest at which antibody binding to a peptide does not hamper the availability of neigbouring peptides. With an occupied area of $0.21 \mathrm{~nm}^{2}$ per bound thiol derivative [5], the average nearest-neighbour peptide distance at $3 \mathrm{~mol} \%$ $A$ is approximately $10 \mathrm{~nm}$, which is not too far from the dimensions of the antibody molecule. However, when the response is normalized to the peptide surface density, we find a ratio of 0.4 bound Mab per peptide, contrary to what is expected for an ideal SAR. We believe that an important reason for this discrepancy is our finding from a Monte-Carlo simulation that there is a fairly wide distribution of nearest-neighbour distances around the average, such that a non-negligible fraction of peptides has its nearest-neighbour distance appreciably below the average value.

However, from a practical viewpoint the use of an ordered SAR improves the surface affinity dramatically: Fig. 3 clearly demonstrates that the SAR is capable of

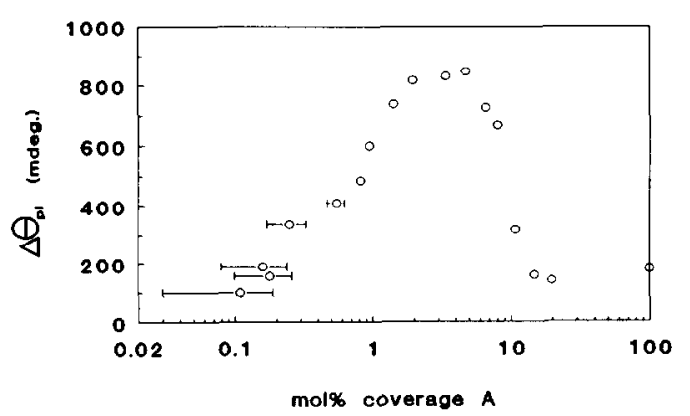

Fig. 3. Response to $67 \mathrm{nM}$ Mab A-16 for different coverages of adsorbate A in A/C-SAR adsorbed compounds. The error bars result from the angular resolution limit of the SPR set up during monitoring of SAR formation. 


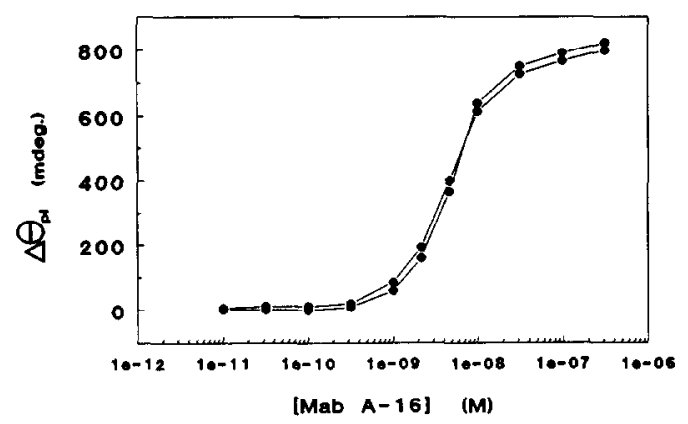

Fig. 4. Binding isotherm of Mab A-16 to an SAR consisting of $A: C=1: 25$. The lines are intended to guide the eye. Note the excellent reproducibility of two separate series.

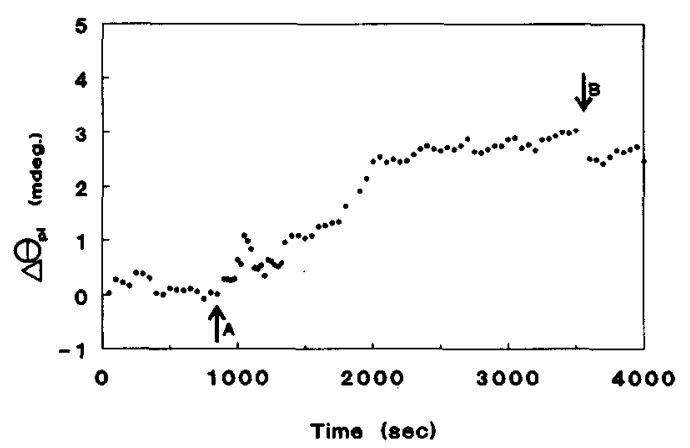

Fig. 5. Response to $10 \mathrm{pM}$ Mab A-16 for an SAR consisting of A:C $\approx 1: 100$ : $\mathrm{A}$ addition of antibody, $\mathrm{B}$ washing.

specific binding of a complete monolayer of target molecule. This should be contrasted with previous experiments where receptor layers were adsorbed or covalently linked to underlying substrates: here only fractions of monolayers could be specifically bound [16, 17].

Figure 4 depicts the binding curve of Mab-16 at a $3 \mathrm{~mol} \%$ coverage of A. From this figurc an affinity constant approximately $2 \times 10^{8} \mathrm{M}^{-1}$ can be determined, not uncommon for an immunoreaction. The larger surface density of active, well oriented peptides permitted us to measure very low coverages of Mab, resulting in a detection limit of $10^{-11} \mathrm{M}$ of antibody (see Fig. 5).

\subsection{SARs to lysozyme}

The main difference from the above-described case is that lysozyme is a much smaller target molecule (MW $\approx 14 \mathrm{kD}$ ). Figure 6 shows preliminary results for this system. Although the scatter in the different data points is fairly large, two observations can be made. (i) The response to the SAR composed of compounds B and $\mathrm{C}$ (Fig. 6(a)) is, contrary to expectations, not very much larger than that to the "dummy" SAR composed of D and C (Fig. 6(b)). (ii) Particularly in Fig. 6(a), the interaction between SAR and lysozyme is largely reversible: at approximately $5 \mathrm{~mol} \%$ coverage of $\mathrm{B}$ more

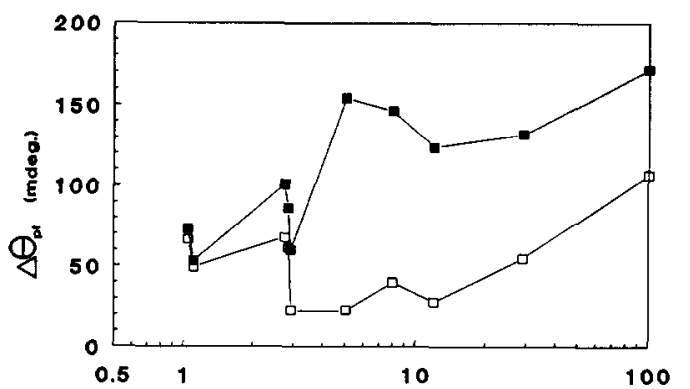

(a) coverage (mol\% peptide)

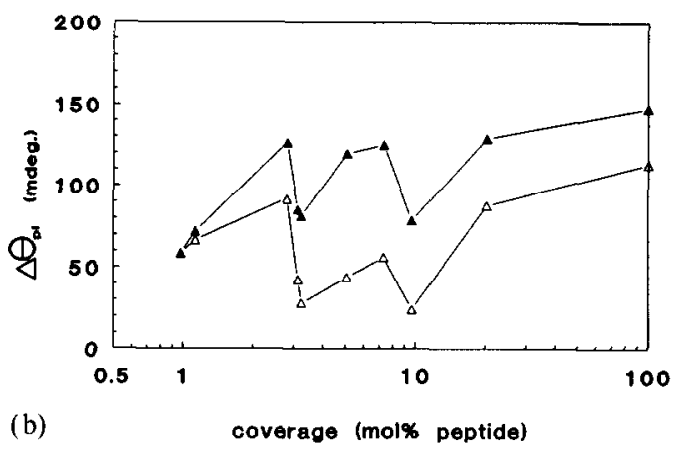

Fig. 6. Response to $1 \mu \mathrm{M}$ lysozyme for various compositions of SAR: (a) $\mathrm{SAR}=\mathrm{B} / \mathrm{C}$, (b) $\mathrm{SAR}=$ dummy $/ \mathrm{C}$. Solid symbols show the response before washing, open symbols show the response after washing step.

than $80 \%$ of the bound lysozyme can be removed by washing.

Figure 7 shows the result when a $10 \mathrm{~mol} \% \mathrm{~B} / \mathrm{C}$ SAR is treated with the enzyme trypsine. We see a decrease in the SAR thickness which can be interpreted as a lysis of peptide $B$ at the lysine moiety. From the known structure of peptide B [18] it can then be concluded that five residues are removed from the peptide. As seen in Fig. 8, the $10^{-6} \mathrm{M}$ lysozyme response to a thus modified SAR is comparable with that when no peptide is present. Now, both the "dummy" and the trypsine treated SAR have a hydrophilicity comparable with that of the "C" SAR, and thus the strong hydrophobic interaction of lysozyme with all these surfaces is

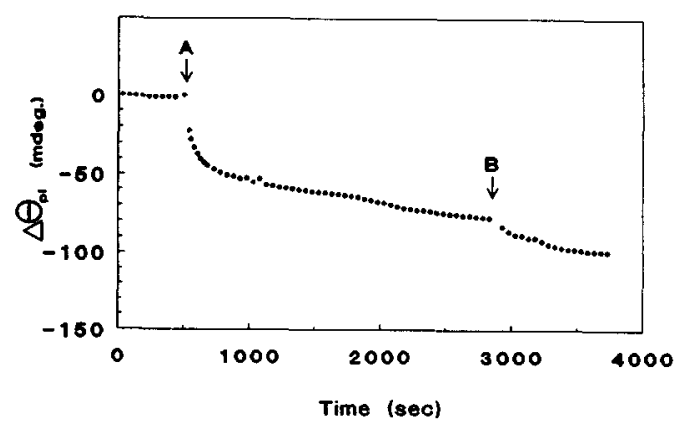

Fig. 7. Effect of the addition of $1 \mu \mathrm{M}$ trypsine to an SAR consisting of $\mathrm{A}: \mathrm{C}=1: 10$. A Addition of trypsine, B Washing. 


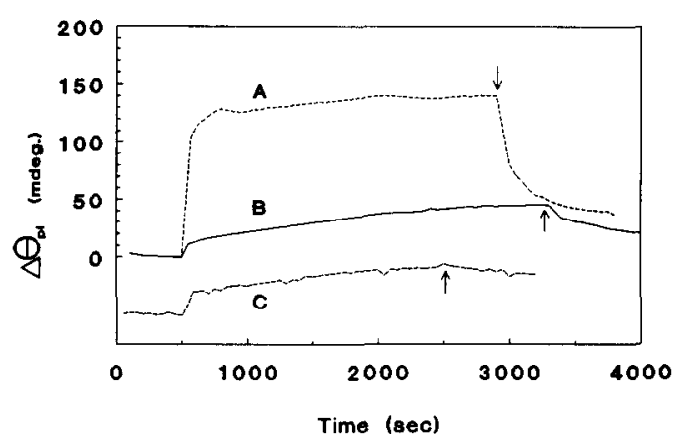

Fig. 8. Response to the addition of $1 \mu \mathrm{M}$ lysozyme at $t=500 \mathrm{~s}$, the arrows correspond to washing steps:

Curve A, SAR of $\mathrm{B}: \mathrm{C}=1: 10$; curve $\mathrm{B}, \mathrm{SAR}$ of $\mathrm{B}: \mathrm{C}=1: 10$ after trypsine treatment; curve $\mathrm{C}, \mathrm{SAR}$ of $\mathrm{C}$.

For clarity curve $C$ has been shifted downward.

roughly the same. Furthermore, it can be sccn from Fig. 8, curves $\mathrm{B}$ and $\mathrm{C}$, that lysozyme is hardly removed after washing, which is in line with the results of lysozyme adsorption on a hydrophobic surface (data not shown). Also, electrostatic interactions are relatively unimportant, in view of the fact that at approximately $\mathrm{pH} 4$ similar behaviour was found. It therefore seems highly probable that the results of both Fig. 6(a) and Fig. 6(b) represent a specific immunoresponse of lysozyme to the underlying SAR, while in Fig. 6(b) a certain proportion corresponds to a hydrophobic interaction. From the existing model for the lysozyme-compound $B$ interaction [18] it can be inferred that not all residues in $B$ participate in the binding. This allows for some freedom in the possibility of finding other peptide sequences exhibiting alternative specific interactions with lysozyme; possibly the "dummy" peptide could be one of these. It is clear, however, that in order to substantiate these speculations, additional experiments are necessary, where the nature of the interactions and their affinity constants are more thoroughly investigated.

\section{Conclusions}

From the present work the following main conclusions can be drawn.

(1) Synthetic peptides coupled to a self-assembling thiol compound provide a highly effective receptor layer which can allow for sensitive recognition of a target molecule. Such an ordered receptor surface is particu- larly compatible with the surface plasmon resonance sensor principle.

(2) The affinity constant of a peptide-target interaction can be of the same order of magnitude as that of an antibody-antigen couple.

(3) From preliminary experiments it can be inferred that the use of small peptides brings into reach a true sensor system where, in contrast to antibody-antigen interactions, the binding is reversible.

\section{Acknowledgments}

This investigation was supportcd by The Netherlands' Technology Foundation (STW), grant GGN99.1924, in the priority programme "Biosensors".

\section{References}

1 J. F. Place, R. M. Sutherland and C. Dahne, Biosensors, 1 (1985) 321-353.

2 C. D. Bain, and G. M Whitesides, Angew. Chem., Int. Ed. Engl.. 28 (1987) 506-512.

3 C. D. Bain, E. B. Troughton, Y.-T. Tao, J. Evall, G. M. Whitesides and R. G. Nuzzo, J. Am. Chem. Soc., 111 (1989) 321-335.

4 L. Häussling, H. Ringsdorf, F. J. Schmidt and W. Knoll, Langmuir, 7 (1991) 1873-1840.

5 C. A. Alves, E. L. Smith and M. D. Porter, J. Am. Chem. Soc., 114 (1992) 1222-1227,

6 L. Bertilsson and B. Liedberg, Langmuir, 9 (1993) 141-149.

7 K. Edinger, A. Gölzhäuser, K. Demota, Ch. Wöll and M. Grunze, Langmuir, 9 (1993) 4-8.

8 A. J. Scheffer, personal communication, 1992.

9 G. W. Welling, J. van Gorkum, R. A. Damhof, J. W. Drijfhout, W. Bloemhoff and S. Welling-Wester, J. Chromatogr., 548 (1991) 235.

10 G. W. Welling, T. Geurts, J. van Gorkum, R. A. Damhof, J. W. Drijfhout, J. W. Bloemhoff and S. Welling-Wester, $J$ Chromatogr., 512 (1990) 337-343.

11 D. J. Van den Heuvel, R. P. H. Kooyman, J. W. Drijfhout and G. W. Welling, Anal. Biochem., in press.

12 R. P. II. Kooyman, A. T. M. Lenferink R. G. Ecnink and J. Greve, Anal. Chem., 63 (1991) 83-85.

13 A. T. M. Lenferink, R. P. H. Kooyman and J. Greve, Sens Actuat. B, 3 (1991) 261-265.

14 H. Raether, Surface Plasmons, Springer Tracts in Modern Physics, Vol. 11, Spinger, Berlin, 1988.

15 B. Liedberg, C. Nylander and I. Lundström, Sens Actuat., 4 (1983) 299-304.

16 R. P. H. Kooyman, H. Kolkman, J. Van Gent and J. Greve, Anal. Chim. Acta, 213 (1988) 35-45.

17 R. G. Heideman, R. P. H. Kooyman and J. Greve, Sens. Actuat $B, 10$ (1993) 209-217.

18 M. J. Darsley and A. R. Rees, EMBO. J., 4 (1985) 383-392. 